\title{
A Case of Mucosa-Associated Lymphoid Tissue Lymphoma of the Bladder: An Extremely Rare Presentation
}

Shobha Mandal ${ }^{1}$, Chandrakala Dadeboyina ${ }^{1}$, Srijana Baniya Sharma ${ }^{2}$, Suryakala Dadeboyina ${ }^{3}$, Joyson Poulose ${ }^{4}$

1. Internal Medicine, Guthrie Robert Packer Hospital, Sayre, USA 2. Urgent Care Center, Dr. Paul's Clinic, State College, USA 3. Medicine, Rajiv Gandhi Institute of Medical Sciences, Kadapa, IND 4. Hematology and Oncology, Guthrie Robert Packer Hospital, Sayre, USA

Corresponding author: Shobha Mandal, shobha.mandal@guthrie.org

\begin{abstract}
Extranodal mucosa-associated lymphoid tissue (MALT) is a type of non-Hodgkin's lymphoma (NHL). It commonly involves the GI tract, but the involvement of the urinary bladder is very rare. It comprises less than $1 \%$ of bladder tumors and $0.2 \%$ of extranodal lymphomas. Fewer than a hundred cases are reported so far and limited literature is available on the management. Here we are presenting a gentleman with MALT lymphoma of the urinary bladder who presented with urinary frequency, an urgency which was initially managed as benign prosthetic hyperplasia. Initially, the treatment helped him with improvement in his symptoms. After a recurrence of his symptoms 11 years later, he underwent cystoscopy with biopsy that revealed MALT lymphoma of the bladder and underwent radiotherapy.
\end{abstract}

Review began 07/20/2021 Review ended 07/24/2021 Published 07/30/2021

๑ Copyright 2021 Mandal et al. This is an open access article distributed under the terms of the Creative Commons Attribution License CC-BY 4.0., which permits unrestricted use, distribution, and reproduction in any medium, provided the original author and source are credited.
Categories: Internal Medicine, Urology, Oncology

Keywords: mucosa associated lymphoid tissue, malt, radiotherapy, urinary bladder, urinary frequency

\section{Introduction}

The malignancy of the urinary bladder is mainly epithelial in origin. In nearly $10-20 \%$ of cases, advanced lymphoma of another site metastasizes to the bladder [1]. However, primary lymphoma involving the bladder is very rare. Primary lymphoma of the bladder comprises less than $1 \%$ of bladder tumors and $0.2 \%$ of extranodal lymphomas [1,2]. Extranodal marginal zone lymphoma of mucosa-associated lymphoid tissue (MALT) accounts for 7-8\% of all B-cell lymphoma. In nearly $35 \%$ of cases, it involves the stomach but can also affect eyes, ocular tissue, skin, lungs, breast, salivary gland, thyroid, and bladder [3]. The prevalence of secondary lymphoma of the urinary bladder is prominently seen in females compared to males [4]. Here we are presenting a male diagnosed with primary extranodal MALT lymphoma of the bladder.

\section{Case Presentation}

A 78-year-old gentleman with a past medical history of benign prostatic hypertrophy, type 2 diabetes mellitus, and nicotine dependence started having urinary frequency 10 years back. He was treated with tamsulosin and finasteride but had minimal improvement in his symptoms. Later he was treated with solifenacin that improved his symptoms. He was continued on solifenacin and remained symptoms-free until two years ago when he came to see urology with a complaint of reappearance of urinary frequency and urgency. He was continued on medical treatment but was not helpful. He came to see urology one month later with urinary retention which was initially thought to be due to solifenacin and it was stopped. He underwent an ultrasound of the pelvis which showed a normal bladder wall without thickening or trabeculation. Post-void residual volume was $15 \mathrm{ml}$. He underwent cystoscopy which showed thickening of the lateral wall of prostate and posterior bladder wall erythema. Bladder mass was removed and biopsy was taken from the erythema area which showed findings suggestive of extranodal marginal zone lymphoma of MALT lymphoma with extensive plasmacytic differentiation (Figures 1-2). 


\section{Cureus}

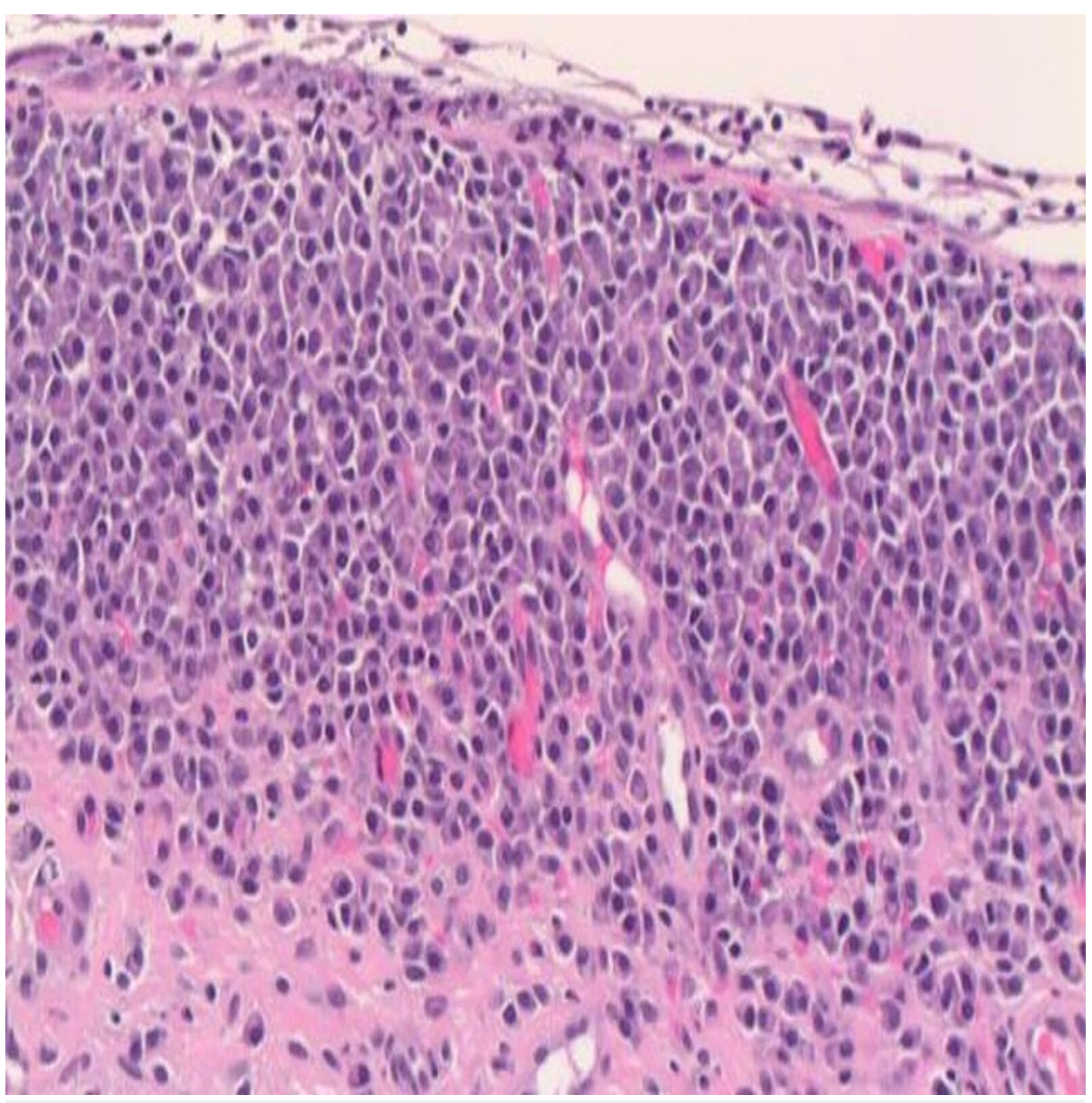

FIGURE 1: Histopathology showing finding suggestive of MALT lymphoma with extensive plasmacytic differentiation. Denuded urothelium with submucosal mature plasma cell infiltration (H\&E X200). MALT: Mucosa-associated lymphoid tissue. 


\section{Cureus}

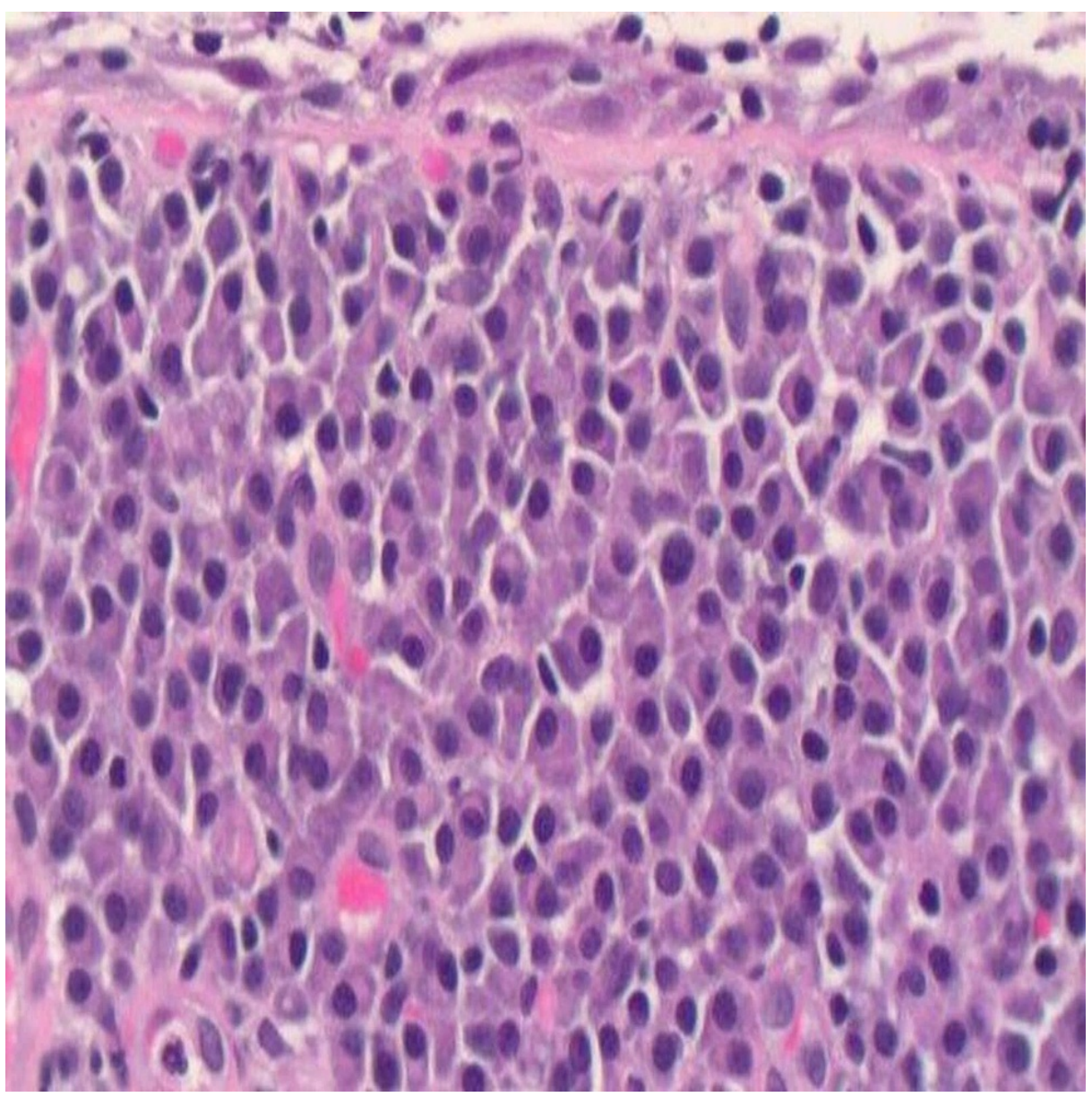

\section{FIGURE 2: Histopathology showing findings suggestive of MALT lymphoma with extensive plasmacytic differentiation. Denuded urothelium with submucosal mature plasma cell infiltration (H\&E X400).}

MALT: Mucosa-associated lymphoid tissue.

Positron emission tomography-computed tomography (PET/CT) showed no gross evidence of locoregional or distant metastasis. Bone marrow aspirate and biopsy of left iliac bone showed no morphological or immunophenotypic evidence of lymphoma in the bone marrow. A diagnosis of primary MALT lymphoma of the bladder was made based on these findings. A wide array of treatment options, ranging from conservative management, surgery, radiation therapy, and chemotherapy with immunomodulators such as rituximab were presented to the patient. The patient opted for radiation therapy and received one cycle of radiation therapy (2400 cGy in 12 fractions). Patient symptoms gradually improved and a follow-up cystoscopy six months later showed prior resection site with no gross evidence of tumor. The patient was monitored for symptoms.

\section{Discussion}

Malignant lymphoma can either be nodal or extranodal. Extranodal malignant lymphoma most commonly involves the GI tract. Other common sites of involvement are the thyroid and salivary glands. Primary malignant lymphoma involving the bladder is a rare entity that constitutes less than $0.2 \%$ of nonHodgkin's lymphoma (NHL) and less than 1\% of bladder tumors [1]. It is unusual with only fewer than 100 cases in literature so far. Primary bladder lymphoma was first discussed in 1885 by Eve and Chaffey $[4,5]$. The two most common types of lymphoma are MALT lymphoma and diffuse large B-cell lymphoma. The first reported case of extranodal MALT lymphoma of the bladder was in 1990 by Kempton et al. [5]. Chronic irritation leading to antigenic stimulation of B cells and their proliferation is postulated hypothesis. This mechanism is like MALT lymphoma of GI tissue caused by Helicobacter Pylori, likewise, chronic Hashimoto's thyroiditis leading to a lymphoma of the thyroid gland and Sjogren's syndrome leading to salivary gland lymphoma [1]. It has a female predominance with a 3:1 ratio. Sixty years and older are affected the most. Nearly $74 \%$ of individuals present with hematuria. Other presenting symptoms include dysuria, urinary frequency, and nocturia. 
Given the rarity of this tumor, a limited literature review is present and there is no standard protocol for the management of the tumor. Treatment approaches are variable, and patients were treated with approaches including surgical excision of the tumor, chemotherapy, radiation, antibiotics, or combined modality in different cases with complete remission [6]. A clear-cut consensus is not available about a standard treatment plan for such patients and the efficacy of one treatment over the other hasn't been determined yet. In a few case reports, patients were treated with antibiotics aiming for H. pylori leading to complete remission. Radiation to malignant lymphomas involving the extranodal sites has shown an excellent response $[7,8]$. Patients of the reproductive age group who are at risk of radiation therapyinduced infertility can be considered for treatment with chemotherapy and immunotherapy. It is believed that patients with systematic spread or recurrence of tumors will benefit from chemotherapy $[9,10]$. A CD20specific recombinant monoclonal antibody, rituximab, has shown promising effects with no evidence of recurrence as well [11]. Timely diagnosis and treatment of MALT lymphoma of the bladder have a favorable prognosis. In a few of the cases, the tumor has also transformed into malignant diffuse large Bcell lymphoma [11,12].

\section{Conclusions}

Primary lymphoma involving the bladder is a very rare presentation. MALT lymphoma involving the bladder has a favorable prognosis if treated with chemotherapy, radiation, or surgery timely. Limited literature is available on the presentation and management hence more research is needed to know more about this rare malignancy.

\section{Additional Information \\ Disclosures}

Human subjects: Consent was obtained or waived by all participants in this study. Conflicts of interest: In compliance with the ICMJE uniform disclosure form, all authors declare the following: Payment/services info: All authors have declared that no financial support was received from any organization for the submitted work. Financial relationships: All authors have declared that they have no financial relationships at present or within the previous three years with any organizations that might have an interest in the submitted work. Other relationships: All authors have declared that there are no other relationships or activities that could appear to have influenced the submitted work.

\section{References}

1. Horasanli K, Kadihasanoglu M, Aksakal OT, Ozagari A, Miroglu C: A case of primary lymphoma of the bladder managed with multimodal therapy. Nat Clin Pract Urol. 2008, 5:167-170. 10.1038/ncpuro1035

2. Combaz N, Kuhn A: Case report about a primary bladder lymphoma . Int Arch Urol Complic. 2017, 3:1-6. $10.23937 / 2469-5742 / 1510030$

3. Khalil MO, Morton LM, Devesa SS, Check DP, Curtis RE, Weisenburger DD, Dores GM: Incidence of marginal zone lymphoma in the United States, 2001-2009 with a focus on primary anatomic site. Br J Haematol. 2014, 165:67-77. 10.1111/bjh.12730

4. Venyo AK: Lymphoma of the urinary bladder . Adv Urol. 2014, 2014:327917. 10.1155/2014/327917

5. Cohen DD, Lamarre C, Lamarre L, Saad F: Primary low-grade B-cell lymphoma of the urinary bladder: case report and literature review. Can J Urol. 2002, 9:1694-1697.

6. Ozawa M, Suenaga S, Ishii T, Suzuki H, Tsuchiya N, Ohtake H: [Primary malignant lymphoma of the bladder diagnosed by transurethral bladder tumor resection: a case report]. Nihon Hinyokika Gakkai Zasshi. 2018, 109:45-49. 10.5980/jpnjurol.109.45

7. Kiesewetter B, Raderer M: Antibiotic therapy in nongastrointestinal MALT lymphoma: a review of the literature. Blood. 2013, 122:1350-1357. 10.1182/blood-2013-02-486522

8. Yamashita H, Nakagawa K, Asari T, Murakami N, Igaki H, Ohtomo K: Radiotherapy for 41 patients with stages I and II MALT lymphoma: a retrospective study. Radiother Oncol. 2008, 87:412-417. 10.1016/j.radonc.2008.03.012

9. Goda JS, Gospodarowicz M, Pintilie M, et al.: Long-term outcome in localized extranodal mucosa-associated lymphoid tissue lymphomas treated with radiotherapy. Cancer. 2010, 116:3815-3824. 10.1002/cncr.25226

10. Kakuta Y, Katoh T, Saitoh J, Yazawa K, Hosomi M, Itoh K: A case of primary mucosa-associated lymphoid tissue lymphoma of the bladder regressed after rituximab in combination with CHOP chemotherapy. Acta Urologica Japonica. 2006, 52:951-954.

11. Vempati P, Knoll MA, Alqatari M, Strauchen J, Malone AK, Bakst RL: MALT lymphoma of the bladder: a case report and review of the literature. Case Rep Hematol. 2015, 2015:934374. 10.1155/2015/934374

12. Bates AW, Norton AJ, Baithun SI: Malignant lymphoma of the urinary bladder: a clinicopathological study of 11 cases. J Clin Pathol. 2000, 53:458-461. 10.1136/jcp.53.6.458 